\title{
Social Value, the Cultural Component in Natural Resource Management
}

\author{
Susan McIntyre-Tamwoy*
}

\section{$\mathrm{T}$} his article explores an issue of increasing relevance to protected area management, the identification of social value and the incorporation of such values into protected area management strategies. Relationships between people and places are examined in an attempt to define and understand the concepts of 'community' and 'community value' and 'social value', and how these may be linked to nature conservation. The distinction between cultural and natural values is explored, with particular reference to the perception of 'wilderness' in protected area management. How representative areas for future protection may be selected and the implications this has on management agencies and their officials is discussed in the context of the cultural attachment of people to landscapes or places. The article concludes with a statement of the basic shifts in practice required to give greater focus to cultural (social) value in protected area management.

\section{Introduction}

This article explores the role of community and community value or social value in protected area management. It aims to work towards both an understanding of why social value (as a form of cultural heritage value) has not been understood or accepted in protected area management and also to establish the need to better understand and consider social value including local community attachment to protected areas to achieve effective conservation outcomes. 'Local community attachment' may be a subset of the full range of social values attributed to any landscape or seascape. It is often subsumed within assessment of wider Australian or international community values, particularly in relation to landscapes and seascapes of World Heritage stalus, the effect of which is to leave local communities feeling disenfranchised. This article based on current research into the cultural heritage of the Great Barrier Reef World Heritage Area (GBRWHA) (see also Greer et al.), examines the broader issue of social values by addressing them in the more generalised context of protected area management agencies in Australia.

* Susan Mclntyre-Tamwoy is with the School of Archaeology,
4nthropology and Sociology, James Cook University. Townsville.
How to involve communities and indeed who to involve, is becoming a matter for increased discussion in protected area management agencies as they struggle to rationalise scientific approaches to the management of landscapes, ecosystems and biodiversity, with increasing demands from the public to incorporate not only multiple uses within park management regimes but also multiple values. Over the last $12-15$ years there has been increased recognition of the right of communities to participate in decision-making processes. Such initiatives have been enshrined in new legislation and more commonly in departmental procedures (see for example the NSW Catchment Management Act 1989; Burgin 2000; Burgin 2002:1-5; Cullen 1997). In response to this Protected Area Management Agencies have often established committees as a way of incorporating the 'community' (for example Catchment Management Committees in NSW; Ministerial Aboriginal Advisory Committees in Qld). More recently such agencies have begun to grapple with the opportunities and challenges of community based research at least in terms of species management (Lunney and Matthews 2002; Wilson 2002).

Despite the best of intentions, these committees must deal with questions and controversies over 'representation' issues. It is not only the mandate of the committee that may limit its ability to effect change or management decisions, but also the questions surrounding who selects the committee membership and how, and whether or not the people on the committee are iruly 'representative' of the community. Those within agencies often regard committees as a rather undesirable compromise, inflicted as a result of political necessity. There is also the realisation that resources will never be sufficient to ensure that biodiversity conservation goals will be achieved through the protected area reserve system alone. Lunney and Matthews (2002:11) warn:

\footnotetext{
“...the gap between research scientists and community groups working on biodiversity issues will widen to an unbridgeable gap. Although some researchers' do not accept community participation in conserving biodiversity, what is more damaging is the fact that much of the community is rejecting research and researchers when dealing with conservation problems".
}

In this article it is argued that some of the misunderstanding between the community and the 
specialist manager stems from cultural heritage issues specifically the understanding of social value. Local communities often have a deep sense of ownership of 'parks' and some have a deep sense of attachment to particular places within the landscape or to practices that they see as intimately linked to their sense of identity (e.g. see Knowles 1997; Veale 2001; Harrison 2003).

All government agencies involved in protected area management in Australia have a responsibility to protect the cultural values of the landscape they manage. Even if such responsibilities are not specifically embedded in legislation, there are overriding intergovernmental agreements and legislation at international, Commonwealth and State levels that set the parameters for cultural heritage management. It follows that even if an agency sees its mandate as reflecting a specific natural heritage conservation focus, it is bound to achieve this by baseline conservation and an understanding of the cultural components of the landscape. Examples of the failure of protected area managers to understand and /or translate this responsibility into practice can be found in the 'erasure' of cultural heritage places to create or recreate a concept of wilderness (for a discussion of this in relation to the Tasmanian WHA see Knowles 1997:89). More challenging is the idea that there are cultural values in perceptions of nature. This is evident in debates over 'old growth' and 'rainforest'. Such debates are characterised by scientists attempting to define and regulate these terms in opposition to communities that have a fierce attachment to particular landscapes (McIntyre-Tamwoy 2002).

\section{Relationship between people and places}

While places exist independently in time and space from people, the 'meaning' and significance of places cannot be divorced from human experience and culture. "The landscape is never inert; people engage with it, re-work it, appropriate and contest it. This is part of the way in which identities are created and disputed, whether as individual, group or-nation state." (Bender 1993:3)

In this context the battle between communities and scientists to exercise control and establish their connections to landscapes and ecosystem management can be seen as an iterative cultural process that contributes to the definition of ownership and identity. However, the outcome of such struggles can be costly, with energy and resources wasted in fights centred on control, rather than directed at achieving sound conservation outcomes.
Pocock has described changes in experiences of the visitors to the Great Barrier Reef and a related 'loss of value' (Pocock 2002: 366) and links this to a lack of recognition by Reef managers of the nexus between the cultural and natural aspects of aesthetic value (Pocock 2002:368). Among other sources, her research on aesthetics draws upon documented and often highly personal accounts of individuals experiencing the Reef. These experiences lead to strong attachments that are based on non-scientific engagements, sometimes visual but just as often involving aural and olfactory senses to create a composite sensory image that captures the significance of the place.

Clearly associations between people and landscapes or landscape features may be complex and enduring. Attachment is not always based on an appreciation of either scientific value or resource use. This is particularly true when dealing with long term 'local' or neighbouring communities where individuals or groups may have developed both an individual and collective 'memory' of the protected area based on an experiential engagement of the landscape or seascape over time. The protected area manager must understand that recognising social value and successfully integrating the management of natural and cultural values involves learning from the community as well as educating the community.

\section{What constitutes a community and how do we identify stakeholders?}

Amit and Rapport remind us that anthropologists have long noted the "slipperiness of the notion of community arguing that it is too vague, too variable in its application and definitions to be of much utility as an analytical tool". However they also point out that "like symbols, key lexical terms such as community, nation, and culture persist in usage because they evoke a thick assortment of meanings, presumptions and images" (Amit and Rapport 2002:13).

Anthropologists through the study of colonialism and ethnicity have devoted lengthy discussion to addressing the definition of community (e.g. Keesing 1994; Amit and Rapport 2002:44). Increasingly, archaeologists engaging in community-based archaeology have also devoted much energy to this (Harrison 2002; Greer, Harrison and McIntyre-Tamwoy 2002; McIntyre-Tamwoy 2002) especially in relation to the relationships between community and identity and heritage.

To some extent it is appropriate to define 'community' on a contextual basis. In relation to the GBRWHA the concept of community can be invoked at many levels - the 'world' community, the 'heritage' community, 'local' 
community or the Aboriginal/Torres Strait Islander community. Often we can also treat industry stakeholders as a type of 'community'. Stakeholders may be further defined as separate communities of common interest. It is this heterogeneity that makes engagement with community so challenging (Wilson 2002; Dickman 2002). Knowles (1997) in a case study based on the Tasmanian WHA adopts the term 'communities of interest' to explore the attachment of two geographically based communities, two activity based communities (bushwalkers and anglers) and a philosophically defined community (environmentalists) to the WHA.

The project on which this article is based (reported more fully elsewhere: McIntyre-Tamwoy 2004; McIntyreTamwoy in prep) explores 'local attachment' and therefore defines the community in terms of a local, geographically bounded area adjacent to, or overlapping the protected area. Such a community may include a cross section of industry stakeholders, Indigenous and nonindigenous Australians who all share a common geographic residency. Through this geographic catchment, community members will share access to certain protected areas although their beliefs, their use of and attitudes to the landscape, and their expectations of involvement in its management may vary widely. Defining the boundaries of the community both physical and conceptual is a challenge for protected area management agencies and is one of the factors being explored through the James Cook University/CRC Reef project.

Community based approaches have been debated and developed in both the natural and cultural heritage fields for a variety of reasons. These include: the harnessing of the support and attention of communities in relation to heritage objectives; as a way of negotiating permission from communities to carry out research (particularly in relation to indigenous heritage or places); as a means of justifying project objectives and expense to politicians and regulating bureaucrats and other agency overseers; and as a recognition of the ethical issues around community rights (see Greer 1995; Greer 1999; Greer Harrison and McIntyre-Tamwoy 2002; Davidson, Lovell Jones and Bancroft 1995; Dickman 2002; Lunney and Matthews 2002; Wilson 2002).

\section{Heritage, Social Value and Nature Conservation}

Government authorities and regulators use broad definitions of heritage. For example:

\footnotetext{
"Australia's heritage, shaped by nature and history, is an inheritance passed from one generation to the next. It encompasses many things - the way we live, the traditions
}

we hold dear, our history and values. It is also reflected in the natural and cultural diversity of places and objects that help us to understand our past and our effect on the Australian Landscape." (AHC 1998)

In this definition, 'heritage' is seen as an outcome of the interaction of history and nature, reflecting the iterative process of culture acting on the landscape and the landscape acting on culture. In a similar fashion, heritage places are described as:

“...either natural or cultural places. In reality, heritage places usually possess many different values, ranging from natural values at one end of the spectrum through to cultural values at the other. For example, the vast landscape of Kakadu contains important ecosystems, wonderful Aboriginal paintings and engravings, sites of great spiritual significance and interesting historic features. Understanding this complex heritage place means recognising all elements and respecting all values". (AHC 1998)

In recent years language has altered to incorporate 'values', although in practice people documenting and assessing heritage significance often treat values as synonymous with objects or elements. When assessing social values, many practitioners have difficulty in assessing or analysing statements from communities and these are often expressed in terms relating to scientific significance. The tendency then is for experts to correct them rather than to understand and evaluate them (Greer et al. 2002). So in documenting forest places in NSW, communities may express their attachment to places in terms of biodiversity, habitat value or Aboriginal archaeological values because they are aware that these categories of scientific significance are well defined and protected by authorities.

While there are different components to social value, to address and consider social significance effectively, specialist practitioners (whether archaeologists, historians, architects or anthropologists) must realise that community value is determined not by the specialist but by the community. The role of the specialist becomes more challenging, less about power and authority and more about facilitation and articulation. The specialist must draw out and to some extent interpret and articulate what the community sees as important about a place and how they perceive its significance in our past and present. Community value cannot be corrected by the specialist on the grounds of historical fact, or at least not without expensive, costly and (I would argue) questionable 'reeducation' of the community involved. For example, a place may be perceived by a community as symbolic of our settler past and the archaeological finds a fragile, rare and important reaffirmation of that past. While the 
archaeologist may argue that the finds are in fact commonplace and therefore not significant, this is unlikely to convince the community whose beliefs or values about the place are tied to their identity (see for example the case of the Conservatorium of Music discussed in Greer, Harrison and McIntyre-Tamwoy 2002). While it is valid for archaeologists to comment on or correct the scientific or technical value of a site or finds, they are not qualified to correct the social significance or community value as expressed by that community.

In the identification of social values associated with 'heritage' there are no correct or incorrect values. Individuals may not be told that while they might feel they are attached to a place they are actually wrong. Instead, 'thresholds' are used to translate heritage values and places into a regime of statutory protective mechanisms. To some extent these thresholds are discussed and agreed on by the community. For example, the Australian Heritage Council does this, as did its predecessor, the Australian Heritage Commission, through public consultation and the NSW Heritage Office through the cross section of skills and experiences represented on the Heritage Council of NSW. In this way government departments and others involved in heritage management use agreed thresholds to sort places into protective regimes without (at least in theory) challenging individual or group attachment to those places. Protection is given to places that meet the threshold.

The recognition of social value is enshrined in key Australian heritage legisiation, charters and government policies, but until recently it has been largely overlooked in significance assessment and management (for a discussion of this see Byrne et al. 2001). This has led to an inequity in the effective conservation of heritage places and an over emphasis on 'scientific' significance or values (e.g. biodiversity, archaeology) in the identification of conservation priorities. In turn, this has meant that Australian community groups, both Indigenous and non-indigenous, have had to develop an increasingly sophisticated grasp of scientific jargon to secure the conservation of places of value to them.

A fundamental question has been asked about the motivation and rationale that underpins the protection of heritage places (McBryde 1985; Byrne 1993, 1998). Does it protect a select group of places of significance to a specialist elite or places valued by the entire community? The growing demand for the recognition of social significance or community value in management decisions relating to heritage places requires us to think beyond the frameworks that have dominated natural and cultural heritage management in Australia to date.

The debate in the nature conservation arena has followed parallel lines with even more dramatic examples than those in the cultural heritage area. Increased recognition of the importance of nature conservation over the years has given rise to a corresponding increase in the range and number of specialist careers aimed at identifying, understanding, assessing and conserving aspects of nature and biodiversity. Over time this has led to an increase in our detailed understanding of our environment but it has also served to create a divide between those who live and interact with the environment (and who foot the bill for its management) and those who hold authority through specialist knowledge over decisions regarding the environment. At times community groups have felt disenfranchised in the environment debate and decisionmaking. This contestation has been described by Knowles (1997:7) as "tournaments of value". She describes the interactions between the protected area managers and communities as a series of strategies and tactics. Those in power have the advantage of being able to look into the future and can therefore employ strategies. In contrast, local communities may use tactics that depend on employing wit and deception opportunistically.

\section{Local vs State, National and World Heritage Values in Social significance assessment}

The existence of a range of heritage legislation at international, Commonwealth, State and local government levels leads to a tendency to rank and rate values and, as a consequence, to a variable commitment to the conservation of cultural heritage values. For example, it is often argued by managers that the primary conservation objectives of World Heritage Areas are to manage those values reflected in the rationale for its listing. The rationale used is that if the area was set aside because of its "outstanding universal natural values" then this justifies managing the area with little or no regard for its cultural values. This misconception persists despite increasing attempts by the international heritage community to clarify the issue. In the preamble to the conclusions and recommendations arising from the National Committee for UNESCO World Heritage Conference held recently in the Netherlands (22-24May 2003) it was stated that the participants:

\footnotetext{
"Recognise that the World Heritage Convention aims to protect cultural and natural heritage of 'outstanding universal value', but underscored that the whole range of values - including local values, intangible and spiritual
} 
values and traditional management systems - should be fully understood, respected, and taken into account in the process of identification and sustainable management of World Heritage...

Emphasize that universal and local values are part of a continuum, not a hierarchy, and should not be separated. Indeed, it is not viable to identify or manage universal value without acknowledging and maintaining the value of places to local peoples.

Acknowledge that World Heritage properties are dynamic entities where cultural and social values evolve. They should not be frozen in time for purposes of conservation. Indeed, the continuity between the past and future should be integrated in management systems accommodating the possibility for sustainable change, thus ensuring that the evolution of the local value of the place is not impaired." (www.unesco.nl/main6-lphp)

\section{The issue of cultural vs natural values}

The separation of natural and cultural values is largely artificial. Social value is often underpinned by an appreciation of scientific data and rarity. For example, a particular landscape demonstrated by scientists to provide habitat for endangered species may be considered by a community to be very important. But a particular landscape only believed to provide habitat for an endangered species may nevertheless be considered by a community to be equally important. Although scientists may demonstrate that the landscape is not a significant habitat, in the battle for conservation of the area the landscape is likely to take on an indelible significance to the local community. The latter may simply choose not to believe the scientists; alternatively, the terminology may shift regarding the importance of the place. Whatever the outcome, community belief in its value is unlikely to shift. Classic examples of this can be found in the forest conservation debate. Chaelundi State Forest in northern NSW was the scene of well-publicised protests against the logging of native old growth forests. During the Comprehensive Regional Assessment (CRA) of Forests that informed the Regional Forest Agreement (RFA) process in NSW negotiations, it became clear that scientists did not rate the conservation values of this particular piece of forest as highly as other forests under consideration. For this reason the conservation agency, the NSW National Parks and Wildlife Service (NSW NPWS) was not particularly keen to acquire it. On the other hand, NSW State Forests realised that the area had become a symbol for the environment and 'green' groups and that because of its social value it was no longer a viable commercial forest. The agency therefore wanted it considered in the negotiations for land transfers. Horsfall (2002:151-155) discusses some of the issues around overlapping Aboriginal cultural and natural values in the Queensland Wet Tropics World Heritage Area.

In addition to differences in how community and specialists value places, there are different natural conservation categories that reflect the ways in which some sectors of the community see values being managed. One of the clearest examples of the community imbuing nature with social value is the concept of 'wilderness'. The wilderness movement has a distinct philosophical basis. The move to protect natural places as wilderness can be seen as a direct response to the philosophical belief that nature has an intrinsic right to exist, that humans are destructive beings, and that it is imperative to protect nature from humans. This movement has its roots in response to the Enlightenment movement but gained increased momentum in the late 1980 s and into the 1990s. Fields such as 'environmental ethics' seek both to educate and reposition the relationship between human and non-humans. In part this field has emerged as a natural progression from the animal liberation movement. Singer (1975) for example claims that all sentient beings, i.e. those capable of feeling either pleasure or pain, are members of the moral community and possess rights to moral consideration. Deep ecology or the concern for the well being and flourishing of non-human life has emerged as a powerful force in the environmental movement in Australia and overseas. The term "deep ecology" is attributed to Arne Naess (Naess 1986:14 in Sessions 1996:138) and incorporates a fundamental belief that "Humans have no right to reduce this richness and diversity (of life forms) except to satisfy vital needs".

Movements such as Ecofeminism arose with an increasing number of women, often highly literate, middleclass and active, rising to take lead roles in the environmental movement. These movements and the myriad of variations have had a profound effect on the development of protected areas and the various forms of conservation legislation in Australia. In NSW for instance it is recognised that legislative initiatives in the last decade, and the policies that drive their implementation have actively sought to modify the anthropocentric focus of environmental law. Farrier $e t$ al. point out that:

\footnotetext{
"The new definitions of 'environment' in the PROTEA [Protection of the Environment Administration Act 1991] and the enactment of legislation like the Threatened Species Conservation ACt 1995, which seeks to protect ecological communities, and the critical habitat of threatened species are the result of a changing consciousness about the interconnectedness of all living
} 
species and systems, encapsulated in a concern for the conservation of biological diversity." (Farrier et al. 2000:15).

The focus of conservation efforts to define and protect 'wilderness' and ensuing public debate over the past decade on this issue have highlighted the polarisation of anthropocentric and ecocentric viewpoints. For most Australians 'wilderness' is a subjective concept and is difficult to define. Whereas biodiversity can easily be understood and explained to the public as the conservation of the variety of life and its complex relationships within an ecosystem, wilderness remains a more emotive term often closely related to aesthetic value. Many people equate the concepts of 'rainforest', 'isolation and ruggedness or inaccessibility' and 'old growth' with wilderness. For many Australians used to life in the city, all national parks outside the metropolitan area will seem to be 'wilderness'. Perhaps of greater concern to many members of the public is the concept of exclusion associated with wilderness areas. Restrictions on access and activities in wilderness areas have led in some areas to significant opposition to the declaration of wilderness areas and associated road closures.

There remains in many protected area management agencies today, a school of thought that says all 'non natural' elements should be removed from a wilderness area (i.e. huts, roads, jetties etc). In some cases this has become a stated management objective (see for instance the discussion relating to the Tasmanian WHA in Knowles 1997:89). In most agencies this conflicts with statutory or regulatory requirements to conserve heritage items and places. While cultural landscapes may exist independent of historic physical evidence, visible signs can become important symbols around which resistance to protected area management strategies may develop. It is interesting to note that the proponents of 'dehumanising' the wilderness parks do not advocate the removal of Aboriginal sites or relics, reflecting a view (of long standing irritation to Aboriginal people) that they are somehow part of nature and can be protected as some sort of natural feature, flora or fauna. In stark contrast to 'deep ecologists', the Aboriginal view of nature is intensely humanised where:

\footnotetext{
"People trace their descent from ancestral beings and carry the responsibility of continuing their actions. In terms of sustainability for example, for many Aboriginal people the thing that needs sustaining is the responsibility of people. to care for the land and fulfill ritual responsibilities. "Care for' in this context is often quite interventionist: it can include burning the landscape, visiting sites and carrying out appropriate ceremonies." (Environment Australia 1998:45)
}

\section{Conserving a Comprehensive, Adequate and Representative Sample of our Environment/World}

Consistency in comparing protected areas across Australia and measuring the level of protection afforded to Australia's natural heritage on a world stage is achieved by the allocation and use of an internationally defined set of management categories, known as IUCN (World Conservation Union) categories. There are six IUCN protected Area Categories: Ia - Strict Nature Reserve; Ib Wilderness Area; II - National Park; III - Natural Monument; IV - Habitat/Species Management Area; V Protected Landscape/Seascape; VI - Managed Resource Protected Area. Only the first four are generally funded under the National Reserve System Program, the Commonwealth/State Government co-operative program for the establishment of protected area reserves.

The aim of all countries that have adopted the IUCN categories is essentially to develop a comprehensive, adequate and representative reserve system, which forms the backbone of their land management and conservation program. The existing names and classifications of park categories in State systems within Australia cannot necessarily be taken to indicate which IUCN category they meet. The various State legislations pre-date the IUCN categories and the level of interventionist management and visitor access in Australian Parks is often defined by management documents (Plans of Management) and restrictions in statutory definitions embedded in legislation.

Despite Cordell's (1994:13-3) rather optimistic assertion that "today the IUCN recognises and accepts the principle that cultural diversity and biological diversity need to be conserved together if they are to prosper", there is little evidence to suggest that this is understood, accepted or translated into protected area management strategies in Australia or other similar parts of the world such as the US and Canada. For many purists in the conservation arena, whether conservationist or scientist, the more restrictive protection categories, i.e. category $l a$ and $b$, are the only categories that provide true long-term protection. Protagonists of this view argue that categories II and V which relate to National Parks and Marine Parks are only effective in conserving natural systems and biodiversity if they restrict recreation and human egress through strict zoning and statutory management plans. Hence there is continued pressure on protected area management organizations (e.g. the QPWS and the NSW NPWS) to effectively elevate category IV and V parks to category I and Il status through increased legislative or regulatory restrictions on use and access. 
While the official definition of protected areas adopted by the Commonwealth government does mention cultural resources, it is secondary to the protection of biodiversity. Protected areas (e.g. national parks, nature reserves and marine parks) are defined internationally as:

"areas of land and /or sea especially dedicated to the protection and maintenance of biological diversity, and of natural and associated cultural resources, and managed through legal or other effective means."

(http:/www.biodiversity.environment.gov.au/protect/intro. htm)

The National Strategy for the Conservation of Australian Biological Diversity (Department of Environment, Sports and Territories 1996) summarises the Commonwealth government's commitment to the conservation of biological diversity. It does not mention cultural heritage except by inference as it relates to Aboriginal and Torres Strait Islander "traditional biological knowledge". Similarly, the definition of the Natural Reserve System (Environment Australia 1999), which is the blueprint through which the Commonwealth and the States seek to design, create and manage the protected area reserve system to achieve Australia's commitment to the conservation of biological diversity, does not mention cultural heritage at all.

Much of our society's current approach to biodiversity springs from the school of 'deep ecology' (Sessions 1996). The dismissal or denial of cultural heritage values by many nature conservationists and scientists is based on the conviction that humans do not have a greater right to exist than any other species and that other species have an equal right to prosper and flourish. It therefore follows that wherever possible natural systems and species should be encouraged and the evidence of human intervention in the landscape eradicated and their further impact prohibited. There are four fundamental characteristics of deep ecology:

"The well-being and flourishing of human and non-human Life on Earth have value in themselves. These values are independent of the non-human world for human purposes.

Richness and diversity of life forms contribute to the realisation of these values and are also values in themselves.

Humans have no right to reduce this richness and diversity except to satisfy vital needs.

The flourishing of human life and cultures is compatible with a substantial decrease of the human population. The flourishing of non-human life requires such a decrease."

(Naess cited in Sessions 1996: 138)

It is relevant to note that the focus in the debate over the rolc of cultural heritage in protected areats is about the evidence of human impact on nature and usually centres on the removal or remediation of Western or post contact cultural heritage. For instance, in a symposium on Wilderness Management one speaker acknowledged that virtually all natural landscapes have been subject to interaction with and exploitation by humans and that the management of such areas should "consider this history" but that in his view there can be:

“...no justification for retaining remnants of exploitative activities in wilderness. If such items are considered to be of heritage value, they should be removed and placed on display elsewhere to demonstrate the priorities of the past generation." (Lembit 1993:189)

The implication here is that the priorities of a previous generation were wrong and are now being put right. There is little or no concern about the intrusion of precontact or so called prehistoric cultural heritage that is easily transformed into the 'natural' realm (see also Byrne 1998:90). The argument is not restricted to the management of wilderness parks but permeates management approaches to many Australian parks and is often most obvious in the years immediately following acquisition during which time the landscape is transformed from non-park to park. In a process of selfanalysis the NSW NPWS, discusses this in relation to the acquisition of pastoral lands and their subsequent management as national parks (Harrison 2002b).

The culmination of the deep ecology approach in Australian conservation is the concept of 'Wilderness'. The primary value recognised in Wilderness protection is biodiversity and the opportunity for that biodiversity to evolve free of human impact and intervention. It would seem however that the ecologists and scientists have taken the concept of wilderness well beyond the definition used by Myles Dunphy, considered by many to be the father of wilderness in Australia:

\footnotetext{
"Wilderness or primitive bushland...one of the really indispensable necessities of modern existence in its soundest sense, for where else can man go to escape his civilization...more and more people want back the forested and mountain wilderness which has been lost...to preserve for the human race that connection with things natural and wholesome which is now more than ever necessary." (Myles Dunphy 1934 cited in Moseley 1994: 205)
}

Somehow the concept has progressed from the idea of natural places in which to revive and restore the human spirit, to places from which all but certain humans should be excluded for the benefit of non-human species. This is a shift from an essentially anthropocentric focus of natural conservation area as 'parks' for human use and enjoyment (respite, recreation and spiritual revival) to a 
focus on conservation for the protection and benefit of non-human species in their own right, often involving the exclusion or restriction of humans from the area. In the latter framework the scientist becomes the arbiter of conservation area identification, reservation and management, because it is the scientist who can 'speak' for the non-human species. In such a framework it is easy to overlook cultural values, to view them as counter to the conservation ethic or as symbols of the threats on the natural non-human world (e.g. pastoral heritage as a symbol of environmental degradation: see for example Harrison 2004).

\section{Implications for Protected Area Management Agencies}

The disinclination of sections of protected area management agencies to either acknowledge the cultural component of the landscapes they manage, or the inherent right of communities to actively participate in the management, can be understood within the context of contested landscapes and the appropriation of landscape by deep ecologists and environmental scientists. The identification and assessment of social values is fundamental to Social Impact Assessment (SIA) relating to proposed development and management initiatives in protected areas and included variously in formal assessment processes (where these are required) such as Reviews of Environmental Factors (REF) and/or Environmental Impact Statements (EISs). All too often however social impact assessment studies focus narrowly on flow-on socio-economic impacts at the expense of the more intangible values of importance to communities. While there is potential for SIA to embrace a consideration of these 'intangible' community values, the current reality, as Cox et al. (2002) point out, is that approaches are widely variable and the greatest opportunities for the improvement of SIA practice resides in community action and scrutiny. In the same vein Dale et al. (1997) point out that community groups are already having an impact on SIA in relation to development projects where community action groups are often well organised and vocal. One may expect a similar intensification of community scrutiny and pressure in relation to the social impact of management plans and regimes in relation to Protected Area Management.

Even if protected area management agencies accept that it is important to consider community values (which may include cultural heritage places of social significance), the questions remain how do they identify them and who is the community? Dickman (2002:40) in considering paradigms for community involvement in natural heritage management points out that in Australia the 'community' is often a heterogenous collection of individuals and groups with competing and often conflicting values. He identifies four themes or approaches in community conservation, i.e. reactive, interactive, proactive and opportunistic. It is the proactive approach that holds the key to the successful long term management of community values in protected areas, although there is an implied referencing of the natural over the cultural, and the specialist over the non-specialist in Dickman's wording which requires further consideration. The proactive approach is favoured as:

\begin{abstract}
"Here community action may be undertaken in the absence of threats to a particular species or habitats, and is often aimed at improving awareness of a conservation issues generally so that the likelihood of future biodiversity loss is reduced. Proactive conservation is seen in the efforts of groups such as field naturalists' clubs, bird watching clubs and local natural history societies, especially where newsletters and other education material are produced for broad distribution." (Dickman 2002:42)
\end{abstract}

Nevertheless a proactive approach that collects and 'shares' information on community values along with other cultural and natural values, in the absence of specific threats or issues will prove the most effective in building a deeply layered knowledge of the cultural and natural values of any protected area, particularly if it is a long term approach or built into a long-term research or permanent management arrangement. Dickman concludes that:

"On its own, scientific research can address only some of the many problems afflicting biodiversity conservation. Conversely community-based action can achieve conservation outcomes more broadly, but lacks a framework to direct and channel the effort effectively. Clearly conservation and biodiversity would be better served if the two approaches were more integrated." (Dickman 2002: 43).

This scenario favours the adoption of the research enterprise paradigm by community conservation organisations thereby bringing scientists and communities together to work towards common goals. This is despite evidence that communities often go to considerable lengths to resist such an approach as it does not adequately address their interests.

Wilson, while still describing the community-based approach to an essentially specialist/ scientist generated conservation project, recognises that a 'shared vision' is essential to the success of the community-based project. This is a team approach to research where all members are equal participants. He points out that the quality of the results will be directly proportional to the effort put 
into communicating, inspiring and instilling commitment and understanding in participants' minds. This must be achieved with a diverse cross section of people who must be built into a team (Wilson 2002:80). I would take this a step further by arguing that a shared vision will be more easily achieved if there is a shared recognition of the range of natural and cultural values and issues. The key is in recognising not only the natural scientific aspects of biodiversity conservation but also the cultural aspects. The latter may include consideration of archaeological and historic values but may also include community values or appreciation of natural features. For example, the Regional Assessment of Forests process in NSW provides a clear example of how community assessments and scientific assessment of natural values can differ in debates over old growth and rain forest. Similarly, certain animal species may be imbued with particular community values so it is unlikely that community conservation groups would accept, for instance, that a community of koalas did not require protection despite an assurance from scientists that population numbers might be locally robust or adequate to sustain the species. Similar arguments surround the issue of dugong populations within the GBRWHA [see for example Innes (in prep)].

Employing more heritage specialists in relevant agencies is only the first step in addressing the imbalance in the status and conservation of natural (scientific) versus cultural values. Even in agencies with relatively large cultural heritage units there is a tendency for approaches to become polarised. What is essential is first, the fostering of meaningful dialogue between natural scientists and heritage specialists (who might include: archaeologists, anthropologists, historians social geographers, conservation architects and other heritage staff); secondly, the development of joint comprehensive assessment and management projects and finally, incorporating the outcomes of heritage research and cooperative projects into the day-to-day management of protected areas.

\section{Conclusion}

Community values are as legitimate although not necessarily the same as scientific values. To understand and embrace this tenet requires a fundamental paradigm shift, a 'sharing of power' in the definition of conservation values that is not usually found in current protected area management agencies. The four basic shifts in approach and practice required to achieve equitable change are:

- Acceptance that it is a base level responsibility of protected area management agencies in Australia to recognise and conserve all heritage values (i.e. both cultural and natural) in a particular landscape (or seascape);

- Recognition that cultural heritage values include the social attachment of people to landscapes, landscape elements and associated cultural practice;

- Extension of the existing practice of documenting, researching and auditing the nature, range and conservation status of natural heritage to achieve a similar level of knowledge and status of cultural heritage; and

- Acceptance that sound and equitable conservation outcomes rely not only on educating the public but also in learning from them, particularly in relation to cultural heritage values and the nature of attachment to landscape.

Perhaps then we will be able to recapture and maintain "one of the really indispensable necessities of modern existence in its soundest sense..." (Dunphy in Mosley 1994), i.e. our deep, sometimes spiritual and often emotional attachment to natural places and the cultural practices that we associate with them.

\section{Acknowledgements}

This article arises from research being undertaken into the Cultural Heritage Values of the Great Barrier Reef World Heritage Area at James Cook University. This research is funded by the Co-operative Research Centre (CRC) for the GBRWHA. Dr Shelley Greer CRC Task leader at JCU provided helpful comments on a draft version.

\section{References}

Amit, V and Rapport N., 2002. The Trouble with Community: Anthropological reflections on Movement, Identity and Collectivity, Pluto Press, London.

Ashmore W. and Knapp, B.A (eds), 1999. Archaeologies of Landscape: Contemporary Perspectives, Blackwell, London.

Australia ICOMOS, 1999. The Burra Charter: The Australia ICOMOS Charter for Places of Cultural Significance. Australia ICOMOS Inc. Burwood, Victoria.

Australian Committee for IUCN, 1998. Natural Heritage Places Handbook: Applying the Australian Natural Heritage Charter to Conserve Places of Natural Significance. Australian Heritage Commission, Canberra.

Australian Heritage Commission, 2000. Protecting Local Places: a Guide for Communities. Australian Heritage Commission, Canberra. 
Bender, B., 1993. Introduction: Landscape Meaning and Action. In Bender, B (ed), Landscape: Politics and Perspectives. Berg, Providence and Oxford.

Bickford, A., Brayshaw, H. and Proudfoot, H., 1998. Thematic Forest History and Heritage Assessment (Non-indigenous) UNE/LNE CRA Regions. NSW Dept of Urban Affairs and Planning and Forest Taskforce, Department of Prime Minister and Cabinet, Sydney:

Burgin, S., 2002. Tragic consequences for conservation of misdefining the term 'community'. In Lunney, D., Dickman, C., and Burgin, S., (eds), 2002. A Clash of Paradigms: Community and research based conservation. Royal Zoological Society of New South Wales.

Byrne, D., Brayshaw, H. and Ireland, T., 2001. Social Significance: a discussion paper. NSW National Parks and Wildlife Service, Hurstville, NSW

Context Pty Ltd., 1998. Community Heritage Values Identification and Assessment project for the Upper and Lower North East Regions, Vol 1 and 2. A report Undertaken for the NSW CRA/RFA Steering Committee. NSW Dept of Urban Affairs and Planning and Forest Taskforce, Department of Prime Minister and Cabinet, Sydney.

Cox,G., Dale, A., and Morrison, T., 2001. Limitation and Opportunity: The institutional basis for social assessment in natural resource management in Australia. In Dale, A., Taylor, N., and Lane, M. (eds) 2001 Social Assessment in Natural Resource Management Institutions. CSIRO Publishing, Melbourne, pp74-92.

Dale, A., Taylor, N., and Lane, M. (eds), 2001. Social Assessment in Natural Resource Management Institutions. CSIRO Publishing, Melbourne.

Davidson, I., Lovell-Jones C., and Bancroft, R. (eds), 1995. Archaeologists and Aborigines Working Together, University of New England Press, Armidale, NSW

Department of Arts Heritage and Environment, 1987. Getting to People: Strategies for Community Environmental Education. AGPS, Canberra.

Department of Environment, Sport and Territories, 1996. The National Strategy for the Conservation of Australia's Biological Diversity. AGPS, Canberra.

Dickman, C., 2002. Community versus research based conservation: what are the paradigms? In Lunney, D., Dickman, C., and Burgin, S. (eds), 2002. A Clash of Paradigms: Community and research based conservation. Royal Zoological Society of New South Wales.

Environment Australia, 1999. Australian Guidelines for establishing the Natural Reserve System. AusInfo, Canberra.

Farrier, D., Lyster, R, Pearson, L. and Lipman, Z.. 2000. The Environmental Law Handbook: Planning and Land Use in New South Wales. Redfern Legal Centre Publishing, Sydney, 3rd edition.

Greer, S., 1995. The Accidental Heritage: Archaeology and Identity in Northern Cape York. Unpub PhD thesis, Department of Anthropology and Archaeology, James Cook University.
Greer, S. 1996. Archaeology, Heritage and Identity In Northern Cape York Peninsula. In Ulm, S., Lilley, I. and Ross, A. (eds), Tempus, vol 6, Australian Archaeology '95 Proceedings of the 1995 Australian Archaeological Association Annual Conference, University of Queensland, Brisbane

Greer, S., and Fuary, M., 1987. The Evolution of Community based archaeology in Northern Cape York Peninsula. Unpub. conference paper presented at the 1987 ANZAAS Conference, Townsville.

Greer, S., Harrington, J., Gibbs, M., Fuary, M., Innes, J., and Roe, D., 2000. Cultural Heritage Values in the Great Barrier Reef Marine Park and World Heritage Area: Recommendations for research and Management. Report to the Great Barrier Reef Marine Park Authority.

Harrison, R., 2002a. Ngarranganni/Ngamungamu/Jilinijarra: 'lost places', recursiveness and hybridity at Old Lamboo pastoral station, southeast Kimberley. Unpublished $\mathrm{PhD}$ thesis, University Western Australia, Perth.

Harrison, R., 2002b. Pastoral Heritage and the NPWS Estate: A cultural heritage discussion paper. NSW National Parks and Wildlife Service, Hurstville, NSW.

Harrison, R., 2003. The archaeology of 'lost places': ruin, memory and the heritage of the Aboriginal diaspora in Australia. Historic Environment 17(1):18-23.

Harrison, R. 2004. A cross-cultural landscape: Shared histories of the pastoral industry in NSW. Studies in the Cultural Construction of Open Space 3. NSW National Parks and Wildlife Service in conjunction with UNSW Press.

Heritage Office NSW, 1999. Heritage: Community Based Heritage Studies: A Guide. Heritage Information Series, NSW Government, Sydney.

Heritage Office NSW, 2001. Assessing Heritage Significance: a NSW Heritage Manual update. NSW Government, Sydney.

Horsfall, N., 2002. Cultural or natural? The Applicability of World Heritage Criteria to Aboriginal Cultural Values in the Wet Tropics. In Ulm, S., Westcott, C., Reid, J., Ross, A., Lilley, I., Prangnell, J. and Kirkwood, L. (eds), Barriers, Borders, Boundaries: Proceedings of the 200I Australian Archaeological Association Annual Conference. Tempus, vol 7. pp151-155.

Innes, J. (in prep). Schism and continuity: a study of the social life of the Great Barrier Reef. PhD thesis James Cook University, Townsville

Keesing, R., 1994. Theories of Culture Revisited. In Borofsky, R. (ed), Assessing Cultural Anthropology, McGraw Hill, New York, pp 298-316.

Knowles. J., 1997. Traditional Practices in the Tasmanian World Heritage Area: A study of five communities and their attachment to the area. Report for the Steering Committee of the Traditional Practices in the World Heritage Area Project.

Lane, M., Dale. A., and Taylor, N., 2001. Social Assessment in Natural Resource Management: Promise, Potentiality and Practice. In Dale, A.. Taylor, N., and Lane, M. (eds), Social Assessment in Natural Resource Management Institutions. CSIRO Publishing, Melbourne, pp 3-12. 
Lunney, D., Dickman, C., and Burgin, S. (eds), 2002. A Clash of Paradigms: Community and research based conservation. Royal Zoological Society of New South Wales.

McIntyre-Tamwoy, S., 2000. Red Devils and White Men. Unpub PhD thesis, Department of Archaeology, Anthropology and Sociology, James Cook University, Townsville.

McIntyre-Tamwoy, S., 2002. Places People Value: Social Significance and Cultural Exchange in post -invasion Australia. in Harrison R and Williamson C (eds), After Captain Cook: The archaeology of the recent Indigenous past in Australia. Sydney University Archaeological Methods Series 8, pp 171-190.

McIntyre-Tamwoy, S., (2004) My Barrier Reef: Exploring the Bowen Community's attachment to the Great Barrier Reef, Historic Environment 17(3).

McIntyre-Tamwoy, S. (in prep) Consulting with Communitiesusing social significance as a way of understanding and managing community interests in the Great Barrier Reef. Report to James Cook University and CRC Reef.

Moore, D.,1975. Archaeologists and Aborigines. Australian Archaeological Association Newsletter 2: 8-10.

Moseley, G., 1994. Reconciling the Interests of Two Cultures: a testing time for the Wilderness Conservation Movement. In Barton, W. (ed) Environment: Wilderness the Future. Papers form the 4th National Wilderness Conference 1993. Colong Foundation for Wilderness, Sydney, pp 205-219.

Naess, A., 1986. The deep ecological movement: some philosophical aspects. Philosophical lnquiry 8: 10-31.

NSW National Parks and Wildlife Service 1997. Aboriginal Heritage Standards and Guidelines Kit.

Pocock, C., 2002. Sense Matters: aesthetic values of the Great Barrier Reef, International Journal of Heritage Studies, 8: 4, 365-381.

Ross, A., and Coghill, S., 2000. Conducting a community based archaeological project: an archaeologist's and a Koenpul man's perspective. In Australian Aboriginal Studies 1 \& 2.

Sessions, R., 1996. Deep Ecology versus Ecofemininsm: Healthy Differences or Incompatible Philosophies? In K.J. Warren (ed), Ecological Feminist Philosophies. Indiana University Press, pp 137-154.

Shiva, V., 1988. Staying alive: Women, ecology and development. Zed Books, London. - ........

Singer, P., 1975. Animal Liberation: A new ethic for our treatment of animals. The New York Review Press, New York.

Sullivan. S., 1975. The state, people and archaeologists. Australian Archaeological Association Newsletter 2: 23-31.

Tasmanian Aboriginal Land Council, 1996. Will you take the next step? In Ulm, S., Lilley, I. and Ross, A. (eds), Australian Archaeology 95: Proceedings of the 1995 Australian Archaeological Association Conference, Tempus Publications. University of Queensland, vol. 6, 293-9.
Thackway, R. and Cresswell, I.D. (eds), 1998. Interim Marine and Coastal Regionalisation for Australia: and ecosystem based classification for marine and coastal environments. IMCRA Technical Group, ANZECC.

Veale, S., 2001. Remembering Country: History and Memory of Towarri National Park. Pluto Press in conjunction with NSW NPWS, Hurstville, NSW.

Warren, K.J., (ed) 1996. Ecological Feminist Philosophies, Indiana University Press, Bloomington and Indianapolis.

Wilson, P., 2002. Community-based research: science conducted as if people really matter. In Lunney, D., Dickman, C., and Burgin, S. (eds) A Clash of Paradigms: Community and research based conservation. Royal Zoological Society of New South Wales.

\section{Websites:}

www.deh.gov.au/parks/nrs/index.html Australian guidelines for establishing the Natural Reserve System (accessed 24th April 2004).

www.unesco.ne/main6-1php. Conclusions and Recommendations of the Conference 'Linking Universal and Local Values: Managing a Sustainable Future for World Heritage', Amsterdam 22-24 May 2003. 